\title{
Protein Fractionation for Quantitative Plasma Proteomics by Semi-Selective Precipitation
}

\author{
Ekaterina Mostovenko*, Hannah C. Scott, Oleg Klychnikov, Hans Dalebout, André M. Deelder and Magnus Palmblad
}

Bio molecular Mass Spectrometry Unit, Department of Parasitology, Leiden University Medical Center, P.O. Box 9600, 2300 RC Leiden, The Netherlands

\begin{abstract}
Blood plasma is a highly complex mixture of proteins, metabolites and lipids, and a rich source of potential biomarkers for a range of diseases and conditions. The wide range in protein abundance poses a tremendous challenge for plasma proteomics. However, as a relatively small number of proteins make up most of the total protein pool, the concentration range can be compressed by depletion of abundant proteins, such as albumin. To reduce sample complexity and increase the protein coverage, we have developed a sample preparation method based on semi-selective precipitation with acetonitrile at different $\mathrm{pH}$ and built a data analysis pipeline, combining different search strategies. The method we propose is reproducible and easily parallelised (high throughput), and may be well suited to fractionate plasma for label-free quantitative proteomics in large clinical studies. Up to $90 \%$ of albumin and other abundant proteins were removed by adding an equal volume of acetonitrile to the samples adjusted to $\mathrm{pH} 5$.
\end{abstract}

Keywords: Blood plasma; Organic precipitation; Tandem mass spectrometry; Proteomics; Taverna

\section{Introduction}

Plasma contains carbohydrates, lipids, salts, vitamins, amino acids, nucleic acids, hormones and around $75 \mathrm{mg} / \mathrm{mL}$ protein [1]. Proteins from tissues leak into the extracellular fluid and are carried through the lymphatic system, to end up in the plasma. The carrier-protein albumin dominates with $45-50 \%$ of the total protein concentration, while immunoglobulin $\mathrm{G}$ and transferrin contribute $8-20 \%$ and $3-7 \%$, respectively [2]. These and other highly abundant, large proteins mask less abundant ones by decreasing their relative concentration, and through effects such as ion suppression in electrospray ionization mass spectrometry. Although changes in the abundant proteins may also be indicative of the physiological status of the organism, [3] lowabundant proteins, for instance from tissue leakage, may mark an early state of a disease such as cancer [4,5]. Although plasma is easily sampled, the concentration range of proteins, spanning from picogram to microgram per millilitre, is a major challenge in clinical proteomics.

Numerous techniques have been suggested and employed to reduce the complexity of the plasma proteome, including depletion of abundant proteins [6], nonspecific enrichment of low-abundant proteins via combinatorial peptide libraries [7] and specific enrichment of targeted peptides after enzymatic digestion [8]. Complexity reduction can be performed by classical methods such as centrifugation or extraction with organic solvents [9] or by immunodepletion [10]. A range of depletion columns, spin cartridges and affinity capture beads for removal of albumin, IgG [11] and many other abundant proteins are commercially available. Several of these commercial kits have previously been compared by Chromy et al. [12] and Björhall et al. [13] for their utility in plasma proteomics. Immunoaffinity is efficient in depleting selected abundant proteins, but in significantly reducing the concentration range of proteins in plasma, many different antibodies are needed. As the immunoaffinity depletion is carried out under native conditions, other less abundant proteins may still be bound to one of the abundant proteins being depleted, for instance, albumin in plasma. Typically, commercial affinity columns use avian IgY antibodies against the most abundant ("top") plasma proteins, and remove from 50\% (anti-albumin only) to $99 \%$ (top-20) of total plasma protein. In theory, assuming a $100 \%$ recovery, low abundance proteins would then be enriched by a factor 2 to 100 , respectively. However, both reproducibly manufacturing and applying columns with a large number of different antibodies is not trivial. For instance, we have previously observed a significant column-to-column variation in commercial affinity depletion columns (unpublished results). Although, this may not be a serious problem in a general exploration of the plasma proteome, or in studies where proteins have been isotopically (or otherwise) labelled prior to the depletion/enrichment step, poor reproducibility obviously poses a serious problem for label-free studies.

Many of the abundant proteins in plasma have molecular weights exceeding $60 \mathrm{kDa}$ (e.g. albumin, transferrin, fibrinogen, IgA, a-2antitrypsin, apolipoproteins, and acid-1-glycoprotein). A simple and semi-selective depletion of many of these large and highly abundant plasma proteins is possible by precipitation using organic solvents such as acetonitrile, and this has indeed been demonstrated in plasma and serum from several species with reproducible results [14-18]. This procedure results in a separation, wherein most of the more soluble low molecular weight proteins are left in the supernatant and the larger proteins precipitate. Acetonitrile has also been shown to release albumin-bound proteins, which could be potential biomarkers [5]. Protein solubility is also affected by $\mathrm{pH}$, ionic strength and temperature [19], and by adjusting one or more of these parameters, the precipitation may be optimized to efficiently remove as much of the abundant proteins such as albumin, as possible in a single step, while maintaining low-abundant proteins in solution. Alternatively, several precipitation steps can be combined for a more efficient depletion of abundant proteins and increased recovery of lowabundant proteins. Semi-selective precipitation may also be tuned to, partition the proteome in two or more complementary fractions with

*Corresponding author: Ekaterina Mostovenko, Biomolecular Mass Spectrometry Unit, Department of Parasitology, Leiden University Medical Center, P.O. Box 9600, 2300 RC Leiden, The Netherlands, E-mail: n.m.palmblad@lumc.nl

Received August 06, 2012; Accepted September 01, 2012; Published September 03, 2012

Citation: Mostovenko E, Scott HC, Klychnikov O, Dalebout H, Deelder AM, et al (2012) Protein Fractionation for Quantitative Plasma Proteomics by Semi-Selective Precipitation. J Proteomics Bioinform 5: 217-221. doi:10.4172/jpb.1000239

Copyright: (c) 2012 Mostovenko E, et al. This is an open-access article distributed under the terms of the Creative Commons Attribution License, which permits unrestricted use, distribution, and reproduction in any medium, provided the original author and source are credited. 
limited overlaps, for increased combined coverage of the proteome. In this work, we focused on the effect of $\mathrm{pH}$ on the plasma depletion by acetonitrile and the method's suitability for clinical applications. Such a simple precipitation procedure is attractive for large scale studies as they are inexpensive, scalable, easy to parallelize, potentially robust and reproducible, and not dependent on expensive affinity separations with concomitant batch-to-batch or column-to-column variation that is problematic for label-free methods.

\section{Materials and Methods}

\section{Sample preparation and organic precipitation}

Human plasma from healthy volunteers was collected into BD Vacutainer ${ }^{\oplus}$ tubes with $18.0 \mathrm{mg} \mathrm{K}_{2}$ EDTA ( $\mathrm{K}_{2} \mathrm{E}$, REF 367525, BD Vacutainer Systems, Plymouth, UK) and immediately spun down at $1,300^{\prime} \mathrm{g}$ for 10 minutes at $21^{\circ} \mathrm{C}$, and $50 \mu \mathrm{l}$ aliquotes were stored at $-80^{\circ} \mathrm{C}$, until use. Samples were thawed at $4^{\circ} \mathrm{C}$ and then centrifuged at $16,100^{\prime} \mathrm{g}$ at $4^{\circ} \mathrm{C}$ for 1 minute. The $\mathrm{pH}$ was adjusted in three identical aliquots to 5.0, 7.0 and 9.0, by adding acetic acid and ammonium hydroxide directly to the sample. Three other aliquots were diluted 1:10 (v: v) with $100 \mathrm{mM}$ ammonium acetate buffer with corresponding $\mathrm{pH}$ 's, to investigate the effect of protein concentration. For protein precipitation, acetonitrile was mixed with the samples in $1: 1$ (v:v) ratio and the samples were vortexed, three times at $1,000 \mathrm{rpm}$ for $5 \mathrm{sec}$, and then incubated for 10 minutes in an ultrasonic bath at room temperature. Vortexing and sonication steps were repeated twice, before the samples were centrifuged at $16,100^{\prime} \mathrm{g}$ at $4^{\circ} \mathrm{C}$ for 10 minutes. The supernatants after precipitation were collected in fresh Eppendorf tubes and both the pellets and the supernatants were lyophilized. The precipitates were vigorously vortexed and sonicated in $100 \mu \mathrm{l}$ BugBuster Master Mix (Novagen, Merck KGaA, Germany) for pellets and $30 \mu \mathrm{l}$ for supernatants. The pellet precipitates were resuspended in a Bullet Blender (Next Advance Inc., Averill Park, NY) with $0.1 \mathrm{~mm}$ glass beads, which were then removed by centrifugation through 30 $\mu \mathrm{m}$ pore size micro-spin columns (Thermo Fisher Scientific, Waltham, $\mathrm{MA})$ at the lowest speed. The protein concentration was then defined using a Bicinchoninic Acid (BCA) protein assay kit (Thermo Fisher Scientific). This protein extraction reagent has been developed for the lysis and protein solubilisation from bacteria, but is routinely used in our laboratory and directly compatible with BCA analysis, SDS-PAGE, tryptic digestion, and samples are easily cleaned up for analysis by Liquid Chromatography-Mass Spectrometry (LC-MS).

\section{SDS-PAGE and in-solution digestion}

Thirty micrograms of protein (BCA) per sample were loaded on a 1-mm 10-well 4-12\% NuPAGE Bis-Tris gel (Invitrogen, Carlsbad, CA). All samples were diluted in $2 \mathrm{X} \mathrm{NuPAGE}^{\circ}$ Sample Buffer (Invitrogen). Proteins were separated in the gel for $1 \mathrm{~h}$ at $180 \mathrm{~V}$. The gel was stained in NuPAGE* Colloidal Blue (Invitrogen, overnight at room temperature and destained with milli-Q water until the background was transparent.

For in-solution tryptic digestion, $20 \mu \mathrm{g}$ of each sample was used. The digestion was performed after DTT reduction $\left(10 \mathrm{mM}, 56^{\circ} \mathrm{C}\right.$ for 45 $\mathrm{min}$ ) and IAA alkylation ( $25 \mathrm{mM}, 1 \mathrm{~h}$ in the dark at room temperature), in $25 \mathrm{mM} \mathrm{ABC}$ with protein to trypsin ratio $20: 1$ for $12 \mathrm{~h}$ at $37^{\circ} \mathrm{C}$. The reaction was then quenched with $5 \mu \mathrm{L}$ of $10 \% \mathrm{TFA}$. The samples were stored at $-35^{\circ} \mathrm{C}$ until analysis.

\section{Liquid chromatography-mass spectrometry}

Peptides derived from all protein digests were separated by splitless parallel reversed phase C18 NanoLC-Ultra 2D plus (Eksigent, Dublin, CA) ultra-high pressure liquid chromatography (PepMap trap columns C18 5-mm, $300 \mu$ m-i.d., Dionex Sunnyvale CA; ChromXP analytical C18 columns $15 \mathrm{~cm}, 300 \mu \mathrm{m}$-i.d., Eksigent), with an additional loading pump for fast sample loading and desalting. Samples were analyzed for 120 min using a linear gradient, from 4 to $33 \%$ acetonitrile in $0.05 \%$ formic acid with flow rate $2 \mu \mathrm{l} / \mathrm{min}$. The MS and MS/MS (CID-only) spectra were recorded on an amaZon ETD high-capacity 3D ion trap with CaptiveSpray source (Bruker Daltonics, Bremen, Germany). The ten most abundant multiply charged species in the $\mathrm{m} / \mathrm{z}$ range 300 1300 , were automatically selected for MS/MS with one minute dynamic exclusion, after having been selected twice.

\section{Data analysis}

The complete experiment was analyzed in a single Taverna scientific workflow [20] (Figures 1 and 2) with all external software installed in their default locations. For each sample, the raw LC-MS/MS files were first converted to mzXML [21] using compassXport 3.0.5 (Bruker). The mzXML files were then processed as in the open source TransProteomic Pipeline (TPP) [22], using both the X!Tandem [22,23] database search engine and the SpectraST spectral library search. With

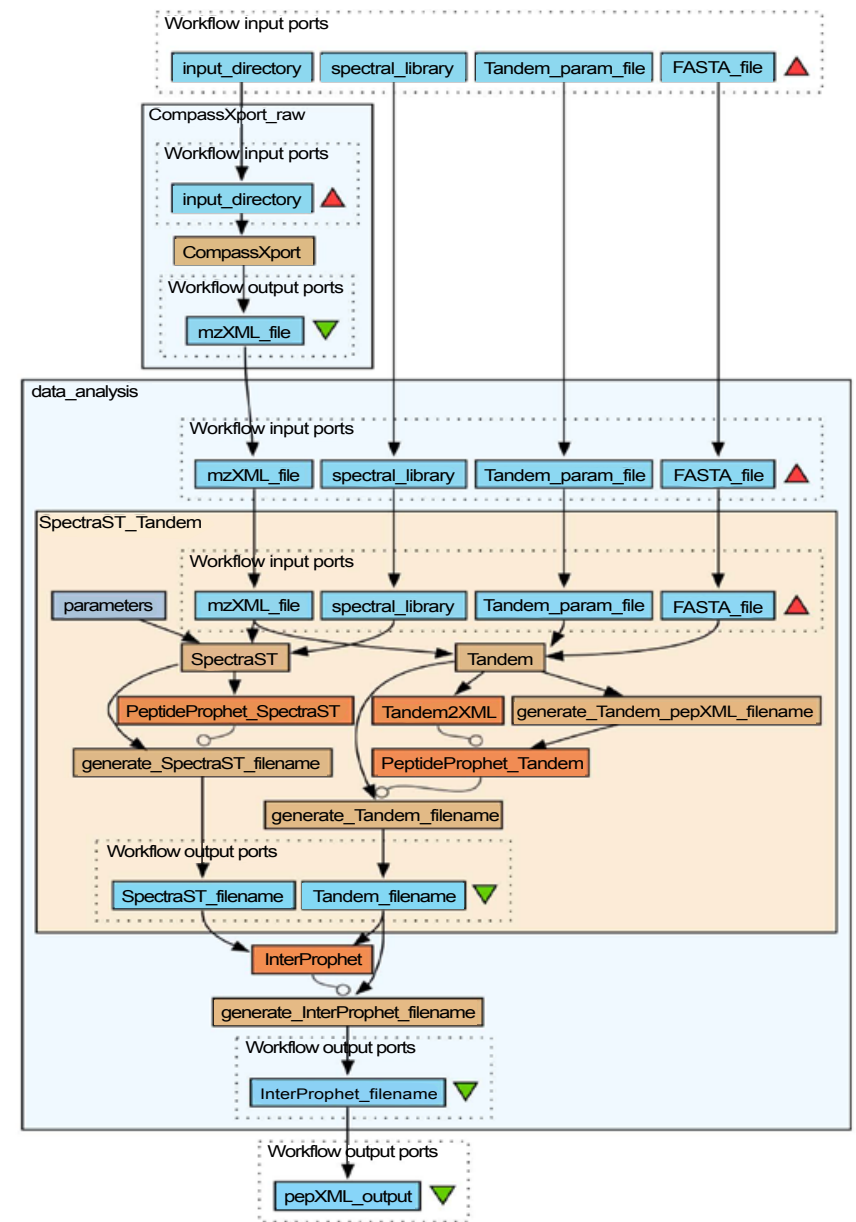

Figure 1: Taverna scientific workflow, for the proteomics data processing based on the TPP. The raw data is converted to the mzXML format by CompassXport and each file is then separately searched by X!Tandem and SpectraST. Only peptides with PeptideProphet probabilities $\geq 0.95$ were included in the further analysis. The separate search results were combined by InterProphet. The workflow allows parallel sample processing. 


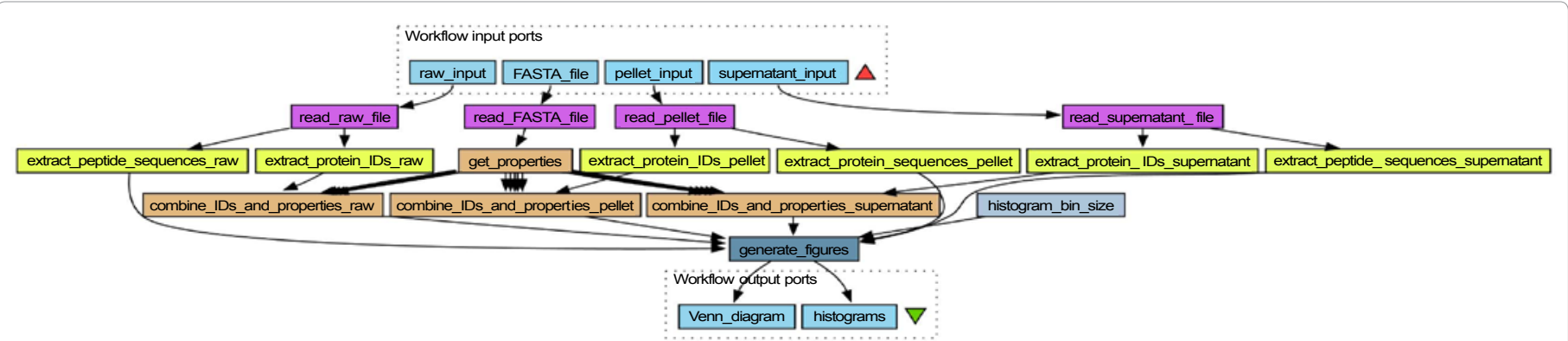

Figure 2: Taverna workflow for producing a Venn diagram and charts of spectral counts as function of protein molecular weight, pl and GRAVY score as seen in Figures 4 and 5 . All inputs are provided from the outputs of the workflow in Figure 1 and the two workflows may be combined into a single, complete workflow.

$\mathrm{X}$ !Tandem, we used the UniProt human reference proteome set (201202-05, canonical sequences only), carbamidomethylation as the only and fixed modification, the k-score plug-in [22] and a monoisotopic mass error $\pm 0.5 \mathrm{Da}$, including the first and second isotopic peaks. For SpectraST, the NIST human spectral library from 2011-05-26 was searched with default settings except for carbamidomethylation ("CAM") of cysteines. All search results (in pepXML [22] ) were analyzed by PeptideProphet [24], then refined and combined by InterProphet. Peptide-spectrum matches with a PeptideProphet probability $\mathrm{p} \geq 0.95$, corresponding to approximately a $1 \%$ false discovery rate (FDR) were included in the analysis. For each protein sequence in the FASTA file, a BeanShell component in the comparison workflow (Figure 2), calculated molecular weight using average masses of amino acids, GRAVY score (using amino acid hydrophathy information from Kyte and Doolittle [25] ) and pI ( using pK values from Bjellqvist et al. [26] ). The protein spectral counts (number of peptide-spectrum matches per protein) in the different fractions, were then compared with respect to this information and visualized using an Rshell. The raw mass spectrometry proteomics data is deposited to the ProteomeXchange Consortium (http://proteomecentral.proteomexchange.org) via the PRIDE partner repository [27] with the dataset identifier PXD000042. The workflow is freely available via www.myExperiment.org ("Plasma Precipitation Analysis").

\section{Results and Discussion}

The method for protein fractionation explored here, was designed to partition the proteins in the sample, reducing the relative abundance of the dominating proteins, and if possible, simultaneously remove contaminants that might interfere with protein quantitation and biomarker detection in body fluids such as plasma. However, at high protein concentrations, such as in plasma, there is always a high risk of co-precipitating otherwise soluble proteins. Experimentally, we indeed found the preparation of diluted samples to be more robust, less timeconsuming and the results were highly reproducible (Figure 3 ). This method, therefore, could be more easily applied in larger studies. The fractionation of proteins in plasma by acetonitrile, is expected to be correlated with the molecular weight and hydrophobicity (at a given $\mathrm{pH})$ of the proteins [28]. It was possible to influence the solubility of different plasma proteins by alternating the $\mathrm{pH}$ of the buffer. For example, proteins with pI 5-6, such as albumin, could be expected to readily precipitate at a $\mathrm{pH}$ of 5 or 7 . Pellets obtained at $\mathrm{pH} 5$ or 7 were relatively easy to resuspend, but precipitates at $\mathrm{pH} 9$ were very hard to dissolve and required additional use of ultrasonication. The reproducibility of protein extraction from $\mathrm{pH} 9$ pellets was also poor, with notable changes in the abundant distribution of the proteins. Plasma $\mathrm{pH}$ in the sample usually varies between 7.5 and 8.5 and not surprisingly its precipitation profiles are most similar at $\mathrm{pH} 9$, where the pellet fraction is not much enriched in large proteins and the supernatant is still highly dominated by albumin (data not shown).

The combination of X!Tandem and SpectraST identified 8,418 spectra (672 unique peptides) in the LC-MS/MS analysis of raw plasma, 6,751 spectra (568 unique peptides) in pellet fraction and 8,799 spectra (463 unique peptides) in the supernatant. As expected, the largest difference or smallest overlap was observed between the precipitate and the supernatant (Figure 4). The total proteome coverage in the pellet and supernatant fractions was $25 \%$ higher, compared to a single analysis of crude plasma. A few peptides and proteins were only identified in the raw plasma, and not in either the pellet or the supernatant fraction. However, relative spectral counts clearly show that most of the abundant proteins precipitate at $\mathrm{pH} 5$ and remain in the pellet, while small proteins are enriched in the supernatant fraction (Figure 5a). Examples of such small proteins include several apolipoproteins (e.g. A1, A2, A4, C1 and C3), as previously shown by Anderson and Hunter [29]. Some mid-range (40-60 kDa) molecular weight proteins also increased in relative abundance in the supernatant. The spectral counts for proteins between 60 and $80 \mathrm{kDa}$ are primarily due to albumin ( $90 \%$ in the raw plasma). The fraction of identified spectra assigned to albumin peptides in the entire raw plasma dataset was close to $60 \%$. In the supernatant sample, only $5 \%$ of the identified spectra were from albumin peptides, indicating a depletion of $~ 90 \%$. Also a number of other large and highly abundant proteins, such as a-2-macroglobulin and complement $\mathrm{C} 3$, were found to be significantly depleted. The relative abundance of albumin in the pellet fraction was approximately the same as for crude plasma.
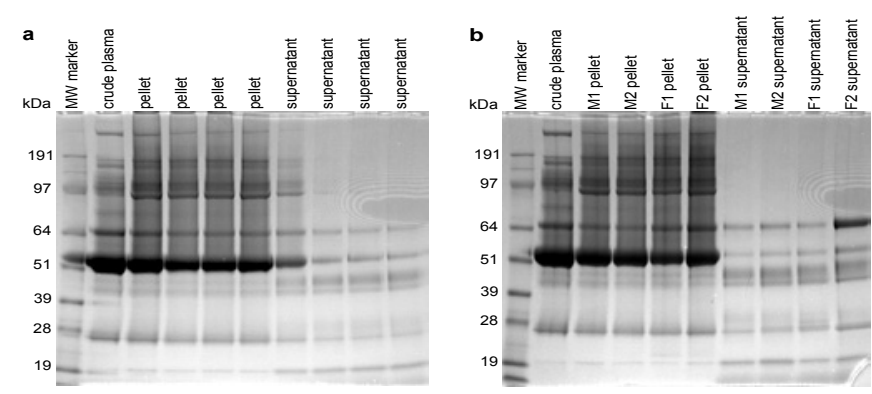

Figure 3: Representative SDS-PAGE gels illustrating the reproducibility of fractionation by acetonitrile precipitation at $\mathrm{pH} 5$ of $20 \mu \mathrm{g}$ human plasma proteins from the same (a) and different (b) healthy volunteers. The $\mathrm{pH}$ of crude plasma samples was adjusted by adding $100 \mathrm{mM}$ ammonium acetate buffer of corresponding $\mathrm{pH}$ in a 1:10 ratio, and then precipitated with an equal volume of acetonitrile. M1 and M2- plasma from male volunteers, F1 and F2- plasma from female volunteers. 
For identifying or quantifying very low abundant proteins, the methods based on immunoaffinity depletion or enrichment, or combinatorial peptide libraries for dynamic range compression are probably superior. However, increasing the relative concentration of already identified proteins tenfold may make it easier to quantify adducts or modifications to these proteins. The precipitation fractionation method could also be used as a first step, before depleting or enriching selected proteins or peptides

Since the $\mathrm{pH}$ for precipitation is easily controlled and can be used to target depletion of abundant proteins, the predicted protein $\mathrm{pI}$ was used to compare the protein content in supernatants and pellets, and to evaluate the method (Figure 5b). Proteins are known to precipitate at the $\mathrm{pH}$ close to their $\mathrm{pI}$ values, and therefore most proteins including albumin were expected to precipitate at $\mathrm{pH} 5$. However, more proteins with $\mathrm{pI}$ 5.0-5.5 were identified in the supernatant fraction than from the pellet. On the other hand, many fewer peptides from proteins with $\mathrm{pI}$ 6.0-6.5 were found in the supernatant, than in the pellet. Interestingly, despite the peaks at $\mathrm{pI} 6.5-7.0,8.0-8.5$ and 9.0-9.5, there were only minor differences between the precipitates generated at different $\mathrm{pH}$. The histogram for raw plasma showed a similar distribution to the sum of the pellet and supernatant fractions, if produced at the same $\mathrm{pH}$ (Figure 5b). Additional information such as the isoelectric point of a protein or its molecular weight, can be used to filter out the erroneous identifications in samples, fractionated in a pI or molecular weightdependent manner. The Trans-Proteomic Pipeline already implements this for $\mathrm{pI}$, at the level of the peptides.

The workflow also calculated the protein hydrophobicity or GRAVY score. When comparing protein abundance in the pellet and the supernatant fractions, with respect to GRAVY score and protein molecular weight, we see somewhat surprisingly, that the hydrophobicity has a very small effect on the precipitation, in comparison with molecular weight (Figure 5c).

\section{Conclusion}

Although blood plasma is one of the most popular sample sources in biomarker discovery, the large dynamic range of the protein concentration provides a serious challenge. As was shown by Kay et al. [28], albumin can be precipitated by simply adding acetonitrile. We have shown that, adjustment of the $\mathrm{pH}$ prior to precipitation and addition of equal volume of acetonitrile was sufficient, to remove

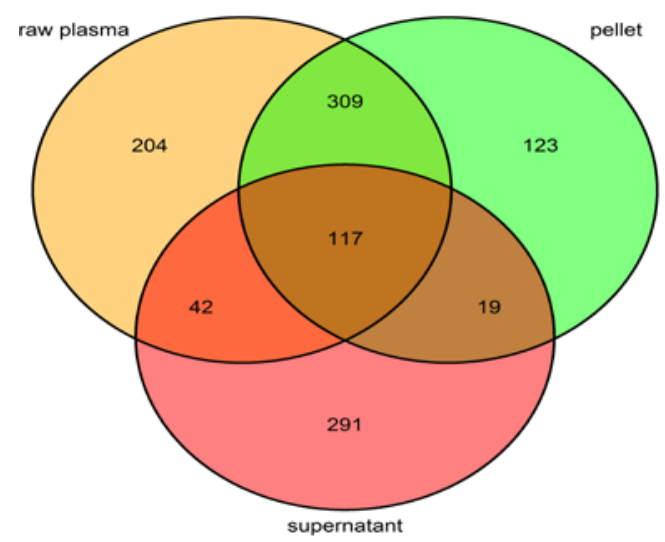

Figure 4: Venn diagram illustrating shared and uniquely identified peptides in the pellet, supernatant and crude plasma samples. The diagram was generated by the workflow described in Figure 2. In total, 6,700-8,800 spectra were identified in each fraction.

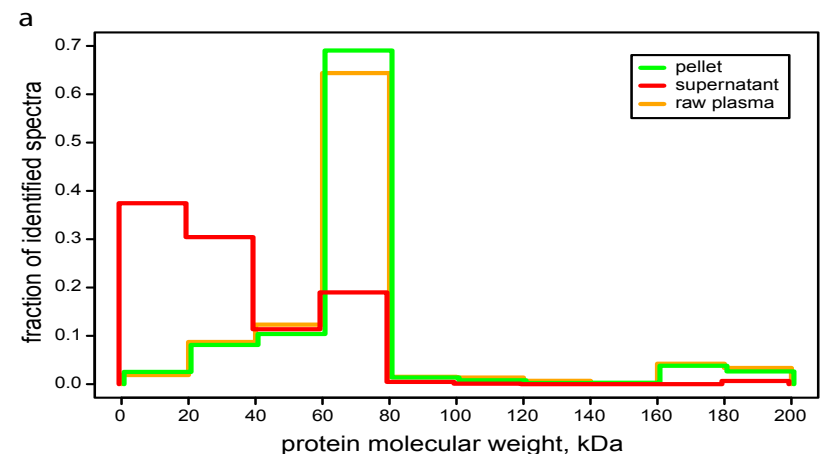

b
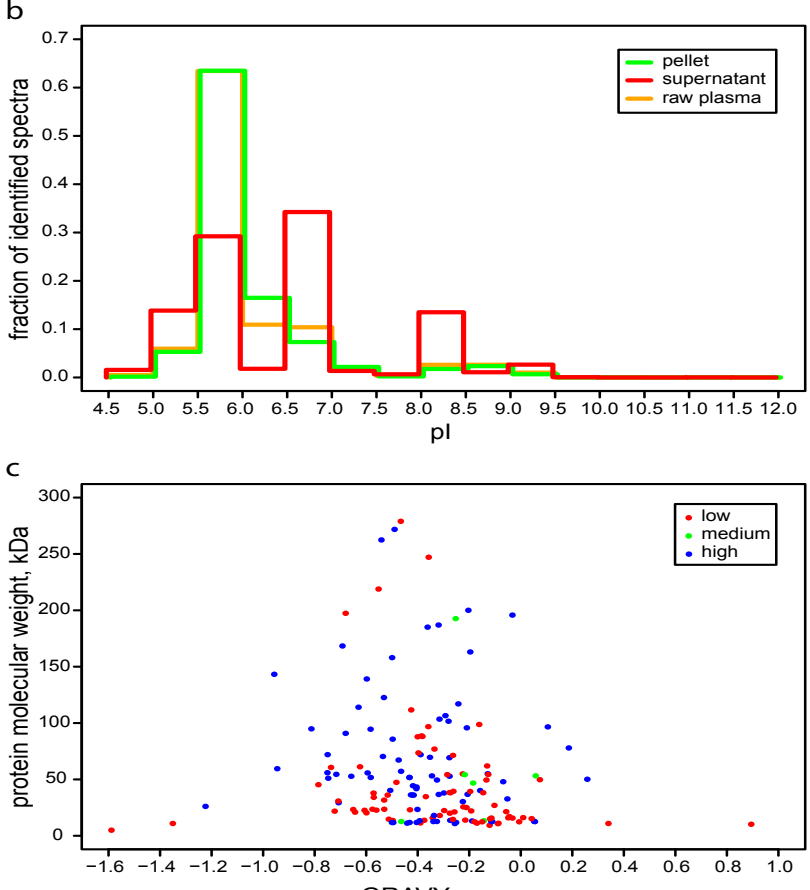

GRAVY score

Figure 5: Histograms of the molecular weight (a) and predicted pl

(b) distributions of proteins identified in the crude sample (orange), pellet (green) and supernatant (red), accompanied by a graph with calculated GRAVY score plotted against protein molecular weight

(c) In the latter, proteins marked in blue have pellet to supernatant spectral count ratio $\geq 2$, in red $\leq 0.5$, and in green more than 0.5 and less than 2 .

approximately $90 \%$ of albumin and many other large proteins from the supernatant extracts. This increases the relative abundance of other proteins, which may be beneficial for quantitative precision, especially in label-free analyses. Moreover, the proteome coverage has been increased by $25 \%$, while identifying $34 \%$ more peptides. The procedure is simple, reproducible, can be quickly performed with common laboratory chemicals and equipment, and is compatible with standard techniques such as SDS-PAGE and LC-MS/MS. The method may be applicable in many types of proteomic analyses of plasma and other samples. For instance, optimised organic precipitation, not only can be used for the sample decomplexification but also to concentrate target proteins, which might be an advantage in biomarker discovery. This method has been successfully implemented in urine proteomics [30]. This method may also be adopted for the preparation of green plant material for mass spectrometry analysis, depleting the highly abundant RuBisCO (Ribulose-1,5-bisphosphate carboxylase oxygenase), as both subunits have isoelectric points near 6 . 
Citation: Mostovenko E, Scott HC, Klychnikov O, Dalebout H, Deelder AM, et al. (2012) Protein Fractionation for Quantitative Plasma Proteomics by Semi-Selective Precipitation. J Proteomics Bioinform 5: 217-221. doi:10.4172/jpb.1000239

Although the gain in protein coverage is lower than what can be achieved with immunoaffinity procedures, it should be emphasized that the present technique is robust and can easily be applied in large clinical studies. Further improvements or adaptation of experimental protocols may focus on specific enrichment for protein modifications (sulfation, phosphorylation, glyco- or lipoproteins), as well as providing some constraints for the peptide/protein identification algorithms, such as limits on $\mathrm{pI}$, molecular weight or post-translational modifications. Further optimization may also aim at improving the quality and albumin depletion of the pellet fraction.

As an additional remark, the Taverna scientific workflow used in this study, contains in a single workflow and interface, all the steps from raw mass spectrometry data through format conversion, peptide identifications, statistical evaluation, data mining to visualization in figures, essentially as they appear in this paper, completely automated and without any interactive manual input. The workflow and the data discussed here are available on-line, enabling anyone to repeat the analysis or adapt the workflow for any other experiment, comparing two or more tandem mass spectrometry datasets, with respect to physico-chemical protein properties.

\section{References}

1. Van Slyke DD, Hiller A, Phillips RA, Hamilton PB, Dole VP, et al. (1949) The estimation of plasma protein concentration from plasma specific gravity. The Journal of Biological Chemistry 183: 331-347.

2. Putnam FW (1975) Alpha, beta, gamma, omega- the roster of the plasma proteins. Academic Press, New York.

3. Roche M, Rondeau P, Singh NR, Tarnus E, Bourdon E (2008) The antioxidant properties of serum albumin. Febs Letters 582: 1783-1787.

4. Petricoin EF, Ardekani AM, Hitt BA, Levine PJ, Fusaro VA, et al. (2002) Use of proteomic patterns in serum to identify ovarian cancer. The Lancet 359: $572-$ 577.

5. Tirumalai RS, Chan KC, Prieto DA, Issaq HJ, Conrads TP, et al. (2003) Characterization of the low molecular weight human serum proteome. Mol Cell Proteomics 2: 1096-1103.

6. Chen YY, Lin SY, Yeh YY, Hsiao HH, Wu CY, et al. (2005) A modified protein precipitation procedure for efficient removal of albumin from serum. Electrophoresis 26: 2117-2127.

7. Guerrier L, Claverol S, Fortis F, Rinalducci S, Timperio AM, et al. (2007) Exploring the platelet proteome via combinatorial, hexapeptide ligand libraries. J Proteome Res 6: 4290-4303.

8. Anderson NL, Anderson NG, Haines LR, Hardie DB, Olafson RW, et al. (2004) Mass spectrometric quantitation of peptides and proteins using Stable Isotope Standards and Capture by Anti-Peptide Antibodies (SISCAPA). J Proteome Res 3: 235-244.

9. Cohn EJ (1941) The properties and functions of the plasma proteins, with a consideration of the methods for their separation and purification. Chem Rev 28: $395-417$

10. Ofosu F, Cassidy K, Blajchman MA, Hirsh J (1980) Immunodepletion of humanplasma factor VIII. Blood 56: 604-607.

11. Eliasson M, Olsson A, Palmcrantz E, Wiberg K, Inganas M, et al. (1988) Chimeric IgG-binding receptors engineered from staphylococcal protein $A$ and streptococcal protein G. J Biol Chem 263: 4323-4327.

12. Chromy BA, Gonzales AD, Perkins J, Choi MW, Corzett MH, et al. (2004) Proteomic analysis of human serum by two-dimensional differential gel electrophoresis after depletion of high-abundant proteins. J Proteome Res 3: $1120-1127$.

13. Björhall K, Miliotis T, Davidsson P (2005) Comparison of different depletion strategies for improved resolution in proteomic analysis of human serum samples. Proteomics 5: 307-317.

14. Michael SE (1962)The isolation of albumin from blood serum or plasma by means of organic solvents. Biochemc J 82: 212-218.

15. Polson C, Sarkar P, Incledon B, Raguvaran V, Grant R (2003) Optimization of protein precipitation based upon effectiveness of protein removal and ionization effect in liquid chromatography-tandem mass spectrometry. J Chromatogr B Analyt Technol Biomed Life Sci 785: 263-275.

16. Alpert AJ, Shukla AK (2003) Precipitation of large, high-abundance proteins from serum with organic solvents. ABRF.

17. Chertov O, Biragyn A, Kwak LW, Simpson JT, Boronina T, et al. (2004) Organic solvent extraction of proteins and peptides from serum as an effective sample preparation for detection and identification of biomarkers by mass spectrometry. Proteomics 4: 1195-1203.

18. Chertov O, Simpson JT, Biragyn A, Conrads TP, Veenstra TD, et al. (2005) Enrichment of low-molecular-weight proteins from biofluids for biomarker discovery. Expert Rev Proteomics 2: 139-145.

19. Jameson $E$ (1937) A phase rule study of the proteins of blood serum: The effect of changes in certain variables. J Gen Physiol 20: 859-877.

20. Oinn T, Addis M, Ferris J, Marvin D, Senger M, et al. (2004) Taverna: a too for the composition and enactment of bioinformatics workflows. Bioinformatics 20: 3045-3054.

21. Pedrioli PG, Eng JK, Hubley R, Vogelzang M, Deutsch EW, et al. (2004) A common open representation of mass spectrometry data and its application to proteomics research. Nat Biotechnol 22: 1459-1466.

22. Keller A, Eng J, Zhang N, Li XJ, Aebersold R (2005) A uniform proteomics MS/ MS analysis platform utilizing open XML file formats. Mol Syst Biol 1.

23. Craig R, Beavis RC (2004) TANDEM: matching proteins with tandem mass spectra. Bioinformatics 20: 1466-1467.

24. Keller A, Nesvizhskii Al, Kolker E and Aebersold R (2002) Empirical statistical model to estimate the accuracy of peptide identifications made by MS/MS and database search. Anal Chem 74: 5383-5392.

25. Kyte J, Doolittle RF (1982) A simple method for displaying the hydropathic character of a protein. J Mol Biol 157: 105-132.

26. Bjellqvist B, Hughes GJ, Pasquali C, Paquet N, Ravier F, et al. (1993) The focusing positions of polypeptides in immobilized $\mathrm{pH}$ gradients can be predicted from their amino acid sequences. Electrophoresis 14: 1023-1031.

27. Vizcaíno JA, Côté R, Reisinger F, Barsnes H, Foster JM, et al. (2010) The Proteomics Identifications database: 2010 update. Nucleic Acids Res 38 D736-D742.

28. Kay R, Barton C, Ratcliffe L, Matharoo-Ball B, Brown P, et al. (2008) Enrichment of low molecular weight serum proteins using acetonitrile precipitation for mass spectrometry based proteomic analysis. Rapid Commun Mass Spectrom 22 3255-3260.

29. Anderson L, Hunter CL (2006) Quantitative mass spectrometric multiple reaction monitoring assays for major plasma proteins. Mol Cell Proteomics 5: 573-588.

30. Thongboonkerd V, Chutipongtanate S, Kanlaya R (2006) Systematic evaluation of sample preparation methods for gel-based human urinary proteomics: quantity, quality, and variability. J Proteome Res 5: 183-191.

Submit your next manuscript and get advantages of OMICS Group submissions

Unique features:

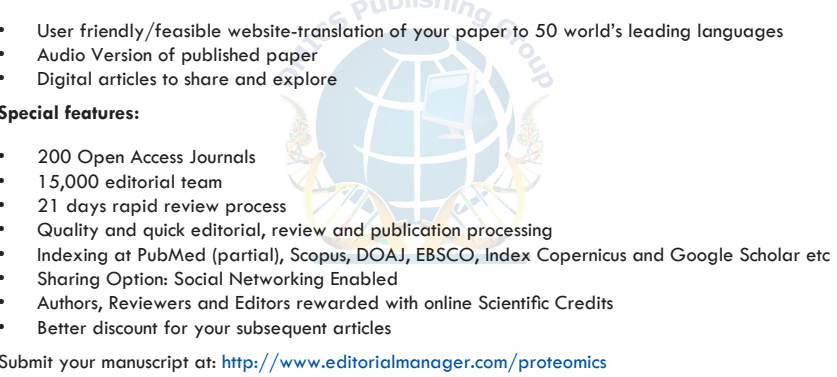

